
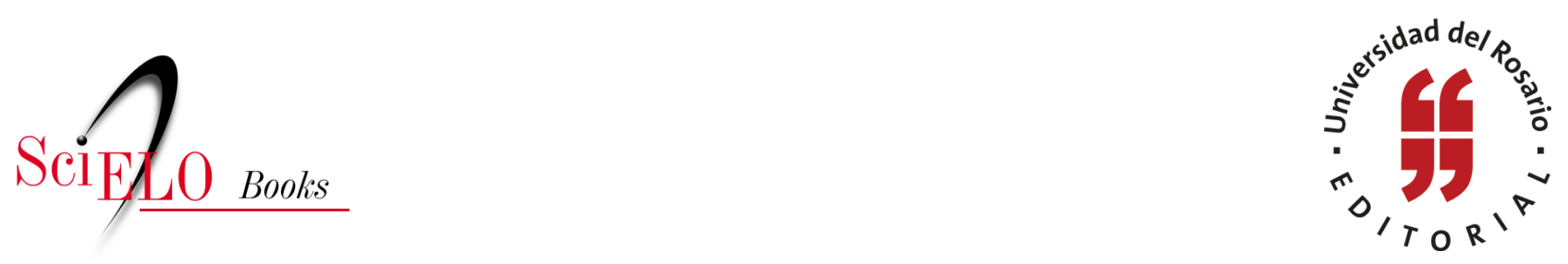

\title{
11. La huelga del 69 (primera parte)
}

\author{
César Augusto Tapias Hernández
}

TAPIAS HERNÁNDEZ, C.A. La huelga del 69 (primera parte). In: Historias de familia: Etnografía delirante sobre el amor, la violencia y las drogas [online]. Bogotá: Editorial Universidad del Rosario, 2014, pp. 45-48. Textos de ciencias humanas collection. ISBN: 978-958-738-543-4. https://doi.org/10.7476/9789587385434.0012.

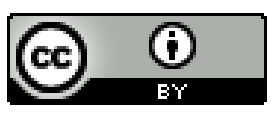

All the contents of this work, except where otherwise noted, is licensed under a Creative Commons Attribution 4.0 International license.

Todo o conteúdo deste trabalho, exceto quando houver ressalva, é publicado sob a licença Creative Commons Atribição 4.0.

Todo el contenido de esta obra, excepto donde se indique lo contrario, está bajo licencia de la licencia Creative Commons Reconocimento 4.0. 


\section{La huelga del 69 (primera parte)}

Existe un movimiento continuo de crecimiento de las fuerzas productivas, de destrucción de las relaciones sociales, de formación de las ideas dominantes; lo unico inmutable es la abstracción de ese movimiento. Carlos Marx, Miseria de la filosofía

Sin duda, esta es una gran historia: de policías y correrías, de amenazas y medidas extremas, de filiaciones casi comunistas luego reivindicadas como errores, la historia de Jaime "Pereque" Fernández, una historia al menos para mí, deslumbrante, una hasta donde el presidente de la República resultó implicado: la huelga en Peldar.

—A uno lo elige la asamblea de trabajadores afiliados — dice el tío Jaime—, así como en cualquier elección. Hay unas planillas con unos nombres, y eso escoge la junta directiva del sindicato; luego, ya entre los elegidos, que son doce, se vota por los puestos: hay cinco miembros principales, cinco suplentes y dos más, quienes asumen la vigilancia.

- ¿Una especie de veeduría o qué?

-En esa época se conocía como junta de vigilancia. Yo entré a Peldar en el 59, más o menos, y la primera vez que me eligieron fui secretario.

- ¿Segundo al mando o qué?

- No, primero estaba el presidente, luego el vice, el secretario era el tercero, luego el tesorero y el fiscal detrás. Pero también llegué a ser presidente, incluso. El sindicato ya había negociado un sueldo de tiempo completo para ese puesto, así que uno no trabajaba propiamente en la empresa, pero en las labores sindicales y la empresa igual le pagaba...

Pero en la huelga de 1969, el tío Jaime era el secretario. Como cada año, el sindicato elaboró un pliego de peticiones para negociar con la empresa. Allí se proponían los aumentos, las primas, los auxilios, en fin... Dice don Jaime que buscaban, 
por ejemplo, que los empleados participaran de las utilidades de la empresa cuando la producción fuera buena, que la empresa mantuviera los fondos para auxilios de vivienda, etc. Ese proceso se llevaba a cabo, dentro de lo normal, a través de las etapas conocidas como arreglo directo, conciliación, prehuelga y hora cero. En aquella oportunidad se agotaron los tres primeras, y se decretó entonces la hora cero...

Por medio de unos papelitos se le informó a cada trabajador la hora de parada, hora que los mismos ejecutivos de la empresa conocían... La negociación sería responsabilidad de unos delegados; dos por parte de la empresa, otros dos del sindicato y uno o dos del gobierno, nombrados en la oficina de trabajo...

Cuando yo llegué a casa del tío Jaime, sin mentir... en busca de esta historia, se me ocurrió preguntar de inmediato por el presidente Lleras. Y mi tío decidió no faltarle al desarrollo cronológico de los acontecimientos; así que mientras que en la licuadora picaba los mangos para los bolis que fabrica, vende y distribuye, yendo de un lado a otro: de la cocina al patio y viceversa, como su hijo Yiyo, andando de un lado a otro... me iba contando que la ley dice que las huelgas se desarrollan afuera de la empresa, en unos campamentos donde deben permanecer los afiliados; pero que, realmente, en la huelga de 1969 se cometieron errores, y reconoce, además, la influencia de un muchacho comunista.

- ¿Qué clase de errores, tío?

-Pues... ¡nos tomamos la empresa!

Normalmente, los negociadores salíamos a las oficinas que quedaban en el centro; pero cuando nos tomamos la empresa, eso se llenó de policías y soldados, y ya no podíamos salir de allí. En tres días acabamos con la dispensa del restaurante y ya luego las mujeres terminaron tirándonos panela por encima de los muros... La negociación continuaba, pues donde estaban todos los trabajadores, y mentiras...

- Como no se llegaba a ningún acuerdo, el plan era secuestrar a los negociadores de la empresa como para forzar la cosa... ¿Me entiende? Otro error, indudablemente. Y cuando paramos los intentos de conciliación y nada de nada, resolvimos colocar parlantes por toda le empresa y apelar al terrorismo psicológico:

-VAmos A PRENDER LA EMPRESA... VAMOS A ACABAR CON TODO... La cosa fue tal que la gente del barrio de la estación se subía pa'l parque de Envigado por puro miedo a que todo el sector estallara... Nosotros negociábamos en una oficina y los miles de empleados dentro rodeándonos. Ese era el cuadro. Los tipos nos decían que los dejáramos salir, que continuáramos al día siguiente y uno de nosotros iba y les decía a los compañeros: “compañeros, ¿qué si paramos hasta 
mañana o pasado?; ique ellos salen y vuelven!”. Y los compañeros, que no. “¡DE AQUí NO SALE NADIE!".

- Hombre, esto es un delito... esto se llama secuestro... apenas decían ellos... estamos cansados, tenemos hambre...

-Y nosotros respondíamos que también estábamos cansados y que también teníamos hambre; pero que nada de nada, el canto de los compañeros era "iACUERDO! ¡ACUERDO! ¡ACUERDO! ¡ACUERDO!

-De entre los que estaban dentro estaban el alcalde de Envigado y un delegado del gobierno nacional. ¡Ah! Y otro más del sindicato, porque según los negociadores nosotros éramos muy sectarios y hasta complicados. De pronto, como si nada, aparece el portero llamando a Óscar Betancur, el presidente del sindicato. -Don Óscar, que pase al teléfono...

$\mathrm{Al}$ rato Óscar llama a mí tío y le dice:

-Oíste, que pasés al teléfono.

-Y ¿eso? ¿Quién es?

—Donde el presidente de la República...

-Yo paso y el señor me dice: "don Jaime Fernández, ¿sabe con quién?”.

- Pues el compañero me dijo que usted dizque era el presidente.

- Sí, señor — contesta él, y de una va como mandando.

- Me hace el favor. Si a las doce de la noche no me salen todos de allá, los saco cadáveres.

- Pero yo no puedo sacar a la gente así no más — le decía yo-. Nosotros también estamos encerrados por los trabajadores; no se trata de hacer lo que nos da la gana... Y bueno...

— ¿Cómo que no? Si yo soy el ¡PRESIDENTE DE LA RePÚbliCA!

—¿Ah, sí? Sí, sí, claro; pero... es que también está el pueblo, como mínimo los congresistas quienes aprueban las leyes sobre las que usted se mueve -le respondía yo.

—Vos cómo que entendés mucho — me decía él...

-Y yo diciéndole que, así mismo, yo no podía hacer nada... que todos los compañeros también estaban dentro...

—Páseme al fiscal —y yo se lo pasé; pero él le dijo lo mismo.

Así suspendimos la negociación en un momento donde ellos subían un poquito y nosotros rebajábamos. Se cedía de a poco, pero nada de acuerdo. Entonces decidimos parar. Ya en medio de esa amenaza, qué íbamos a discutir. A los señores con quienes negociaban los dejaron libres finalmente; pero libres de salir de la 
oficina esa, porque los trabajadores estaban decididos a que los sacaran a todos según el comentario del señor PRESIDENTE DE LA REPÚBLICA, ¡cadáveres! Así, que entre todos movieron los buses de Peldar y los atravesaron sobre los rieles del tren que en aquella época entraba hasta la empresa, y también buscaron candados y cadenas para cerrar bien la puerta...

Ya el tío se desconcentró picando mangos, como medio consciente de su labor, pero embebido en el recuerdo, picó y picó y picó tres veces el mismo vaso de mangos cortados. No los bajó de la licuadora para luego pasarlos por el colador como había hecho con un par de tandas inicialmente, solo se acordaba y prendía de nuevo la licuadora con los mismos mangos y se enchufaba otra vez a la historia... Me dio como pena - es la verdad-. Comparaba al tío con Yiyo y sus acciones repetidas... pero era por contar la historia que se interrumpía su trabajo; ah, pero qué va, el relato resultaba muy interesante... Mi tío Jaime entregado de lleno a la evocación...

- Pasaban las horas, y nosotros veíamos desde adentro cómo aumentaba el pie de fuerza: ambulancias, bomberos, un tren repleto de soldados y perros policía... Llegaron las doce en punto y se vino una grúa delante del tren y pa' dentro. Levantó esa puerta de una y se llevó esos buses por delante, y se llenó eso de policías y de soldados en un segundo, y bueno... nosotros con palos haciendo escándalo y corriendo por esa empresa... Yo corrí con un amigo y nos metimos por el alcantarillado y de allá nos sacó un perro. Todos cagaos vueltos nada... Resulté encanado allá en Envigado. Todos los miles terminamos presos: unos en Bello, otros en la Ladera, en Itagüí y en Envigado. Al otro día nos ubicaron a los principales de la junta y nos llevaron adonde un inspector quien se responsabilizaría de la investigación fruto de la cual habría despidos y presos por los delitos, es decir, los errores cometidos... por el momento teníamos que pagar 30 pesos por cabeza, es decir, por cada uno de los miles, para poder salir de la cárcel y volver al trabajo al día siguiente.

- ¿Esos 30 pesos hoy serían cuánto?

—Unos 30.000, diría yo... 